\title{
GOBIERNO, ILUSTRACIÓN Y VIOLENCIA: UNA MIRADA A LA “TRANSICIÓN POLÍTICA” EN COLOMBIA DESDE EL PROYECTO “ATEMPERADO” DE LA EMANCIPACIÓN
}

\author{
Juan Sebastián Ballén Rodríguez \\ doi: 10.11144/Javeriana.uph35-71.give
}

\section{RESUMEN}

Uno de los trabajos menores que a la vez se ha inmortalizado entre los ensayos más citados en los cursos de historia de la filosofía es la publicación de 1784 titulada Respuesta a la pregunta: ¿Qué es la ilustración? del filósofo alemán Immanuel Kant. Proponemos a continuación una hermenéutica de los principales tópicos y problemas que aborda Kant en este texto fundamental, que conectaremos, adicionalmente, con la tesis que se sustentará en este trabajo, a saber: que la filosofía moderna es un ejercicio de crítica del pensamiento que tiene implicaciones tanto en las miradas educativas como en las apuestas éticas y políticas que procuran encontrar salidas para una sociedad atravesada históricamente por el conflicto armado (como sucede en el caso colombiano), en un escenario complejo donde confluyen crisis económicas y luchas asimétricas y fratricidas a través de las cuales se ha buscado, de forma convencional y no convencional, la obtención del poder político.

Palabrasclave: gobierno; ilustración; violencia; transición política; Colombia

Universidad Cooperativa de Colombia, Villavicencio, Colombia.

Correo electrónico: jballen@javeriana.edu.co

Para citar este artículo: Ballén Rodríguez, J. S. (2018). Gobierno, ilustración y violencia: una mirada a la "transición política" en Colombia desde el proyecto "atemperado" de la emancipación. Universitas Philosophica, 35(71), pp. 113-143. ISSN 0120-5323, ISSN en línea 2346-2426. doi: 10.11144/Javeriana.uph35-71.give 


\title{
GOVERNMENT, ENLIGHTENMENT AND VIOLENCE: A PERSPECTIVE ON COLOMBIA'S "POLITICAL TRANSITION" FROM THE STANDPOINT OF A “TEMPERED” EMANCIPATORY PROJECT
}

\begin{abstract}
One of the minor works that has been immortalized and remains amongst the most cited essays in the history of philosophy courses is the 1874 publication entitled: An Answer to the Question: "What is Enlightenment"? by the German philosopher Immanuel Kant. We propose a hermeneutics of the main topics and problems that Kant addresses in this fundamental text; in addition, we will connect its arguments with the thesis that will be supported in this work: namely, that modern philosophy is an exercise of critical thinking that has implications on the educational views, as well as on the ethical and political bets that aim at finding solutions for a society that has been historically traversed by an armed conflict (as has been the case in Colombia), in a complex scenario where economic crises and asymmetric and fratricidal confrontations have been used, in conventional and unconventional ways, to obtain political power.
\end{abstract}

Keywords: government; enlightenment; violence; political transition; Colombia 
La filosofia como superficie de aparición de una actualidad, la filosofía como interrogación sobre el sentido filosófico de la actualidad a la cual pertenece el filósofo, la filosofía como interrogación, por parte de este, de ese "nosotros", del que él forma parte y con respecto al cual tiene que situarse; esto es, me parece, lo que caracteriza a la filosofia como discurso de la modernidad, como discurso sobre la modernidad. Michel Foucault. El gobierno de si y de los otros.

\section{Hipótesis de lectura}

UnO DE LOS TRABAJOS MENORES que a la vez se ha inmortalizado entre los ensayos más citados en los cursos de historia de la filosofía es la publicación de 1784 titulada Respuesta a la pregunta ¿Qué es la ilustración? del filósofo alemán Immanuel Kant (1999). Proponemos a continuación una hermenéutica de los principales temas y problemas que aborda Kant en este bello texto en función de la tesis que se sustentará en este trabajo. Sostendremos que la filosofía moderna es un ejercicio de crítica del pensamiento que tiene implicaciones en las miradas educativas y en las apuestas éticas y políticas que propenden por salidas para una sociedad, como la colombiana, atravesada históricamente por el conflicto armado, en un escenario complejo donde confluyen crisis económicas y luchas asimétricas y fratricidas a través de las cuales se ha buscado la obtención del poder político de forma convencional y no convencional.

Ecos de estas ideas resonarán con fuerza en una teoría del gobierno que tiene origen en la pregunta de cómo conducir a un pueblo bajo la égida de la razón ilustrada. Pretendemos situar el análisis de la violencia y del conflicto armado que ha vivido Colombia por más de cincuenta años en el contexto del proyecto filosófico de la emancipación, esto es, en la perspectiva de una teoría sobre el ejercicio del poder político fundado en postulados kantianos.

Proyecciones contemporáneas de estas ideas se encuentran en la propuesta habermasiana de la teoría de la acción comunicativa y especialmente en el uso de los conceptos de comunidad dialogante, mundo de la vida y pragmática de 
la comunicación. Entendemos que la filosofía kantiana, al trasluz de la teoría de Habermas, se presenta como la arcilla para moldear una idea sobre el quehacer ético y filosófico de las instituciones educativas, los grupos de organización política, la praxis teórica de la filosofía y la sociología, las ciencias sociales y de la educación y, en general, de las diversas comunidades académicas y de acción social que han buscado pensar y actuar en procura de agenciar procesos de cambio en una sociedad en posacuerdo político; ello, particularmente desde el proyecto ilustrado, atemperado por una razón comunicativa, cuya apuesta epistemológica busca el fomento de una racionalidad abierta al mundo de la vida, a la teoría de los sentimientos morales y a la crítica y relativización de las posturas que se cocinan en la pragmática comunicativa de las comunidades dialogantes y que Kant situó en el espacio de la sociedad de los lectores, o razón pública.

\section{El caso colombiano y el problema de la 'transición política'}

Algunos diagnósticos formulados por la filosofía en Colombia han señalado el carácter siniestro y contradictorio de la precaria condición política y democrática de nuestro país. Por ejemplo, Estanislao Zuleta, en un ensayo titulado La violencia política en Colombia (1990), planteó que la democracia colombiana ha sido revestida por un manto enigmático. Con ello, Zuleta se refería a una paradoja sustantiva: Colombia es un Estado que reconoce y legitima la libertad de expresión y de organización, garantiza el ejercicio político mediante la división de los poderes ejecutivo, legislativo y judicial, promueve y garantiza la participación de los representantes políticos elegidos por el pueblo, etc. Sin embargo, y bajo la perplejidad que producen los acontecimientos de violencia y el exterminio del disenso político, el Estado no ha logrado realizar plenamente los principios constitutivos de una democracia, valores que, a pesar de la crítica de Zuleta, fueron adoptados en la Constitución de 1991.

¿Por qué ocurre esta crasa y corrupta contradicción social? Zuleta nos sugiere que ello sucede por cuenta de comportamientos sociales que niegan sistemáticamente el cumplimiento de los principios democráticos, actuando en su lugar fuerzas oscuras que delatan el carácter siniestro y terrorífico de la violencia política en Colombia. Así lo describe el filósofo al mostrar, durante el auge del conflicto colombiano a mediados de los años ochenta, la crudeza de la violencia política 
de Estado, animada por el poder económico del narcotráfico y la confrontación militar entre las guerrillas y el consolidado proyecto paramilitar:

Pero esta democracia está auténticamente habitada por el terror en toda la trama de sus relaciones y en todo el territorio nacional. Existe la libertad de prensa, en el sentido de que no hay censura oficial; pero en este momento más de 50 periodistas están amenazados de muerte, 10 han tenido que salir del país por este motivo y 20 han sido asesinados. Tenemos, pues, la censura del terror. Existe la libertad de organización y participación política; pero el único grupo de oposición de izquierda, la Unión Patriótica (UP), fundado en 1986, ha pagado su actividad proselitista con la muerte de cerca de 500 de sus militantes y simpatizantes, entre ellos su dirigente y candidato presidencial, varios congresistas y numerosos diputados y concejales. De modo que también en este caso la oposición legal, reconocida y saludada por el gobierno, está siendo prohibida por el terror (Zuleta, 2003, pp. 120-121).

Sin embargo, esta lectura no dista de los balances que hacen los científicos sociales al momento de pensar el desmoronamiento de un proyecto político de reconciliación en Colombia ${ }^{1}$. Este es el balance que propone una de las tesis históricas del conflicto y que se refleja en el Informe de la Comisión Histórica del Conflicto y sus Víctimas (2015), en donde se declara que el carácter ideológico contrainsurgente y excluyente que ha caracterizado el nacimiento del conflicto armado en Colombia creó las bases para la aparición de una suerte de 'cierre del universo político', categoría de análisis empleada por Sergio de Zubiría Samper (miembro de la Comisión) para explicar la progresiva relación entre política y violencia.

1 Al plantear un proyecto político de la reconciliación y la paz en Colombia nos referimos a los esfuerzos de la academia y de la investigación social por pensar salidas al conflicto que ha permeado a las instituciones del Estado como a las demás estructuras sociales del país por más de cincuenta años. Por mencionar algunas de las investigaciones más relevantes en esta materia, se encuentran los trabajos de Germán Guzmán Campos, Fals Borda y Eduardo Umaña Luna bajo el título La violencia en Colombia (2014); también cabe señalar el estudio de Marco Palacios Entre legitimidad y la violencia en Colombia 1875-1994 (1995). Una de las investigaciones más recientes sobre el tema es la Contribución al entendimiento del conflicto armado en Colombia. Informe de la Comisión Histórica del Conflicto y sus Victimas (2015). 
Una de las notas comunes de este conflicto histórico consiste en formas de gobierno agenciadas por el poder institucional que han minado las posibilidades para la construcción de una vida democrática: esta dominación estatal del poder político ha originado un conjunto de patologías sociales que terminaron por configurar la forma del Estado en Colombia en la primera mitad del siglo $\mathrm{XX}$ bajo la sombra de una serie de violencias que han pervivido a lo largo de la historia política y social del país, y que pueden ser descritas del siguiente modo:

[...] utilización permanente del Estado de sitio, con sus consecuencias devastadoras para la vida democrática, una constante de "miedo a la democracia"; concentración del poder político para el lucro capitalista y el beneficio privado; imposición del bipartidismo y la violencia sectaria; instauración definitiva de la violencia como representación de lo político; incremento del autoritarismo social; degradación de los fundamentos morales de la acción política; crisis de legitimidad del sistema político y electoral; deslegitimación de la justicia y las fuerzas armadas. El cierre del universo político se convierte en "causa eficiente" (Aristóteles) de la profundización y persistencia del conflicto: deslegitimación del campo político; crisis de representación de los partidos políticos; privilegio de la represión y la violencia en la conflictividad política; reducción de lo político a lo estatal; negación de la democracia social y política (de Zubiría, 2015, pp. 221-222).

Este diagnóstico coincide con la conceptualización formulada por Javier Giraldo Moreno S. J., otro miembro de la Comisión Histórica del Conflicto y sus Víctimas, y para quien las investigaciones más recientes sobre la infestación del paramilitarismo en las instituciones colombianas -en particular de la publicación Y refundaron la patria del año 2010, liderada por Claudia López y la Corporación Nuevo Arco Iris-, han demostrado que el narcoparamilitarismo generó una "reconfiguración cooptada del Estado" en donde lo ilegal y lo legal se combinan en función del diseño de políticas públicas y reglas de juego a la medida de una élite criminal.

Para el padre Giraldo (2015), este escenario de corrupción corresponde al comportamiento de una persona que padece de esquizofrenia, patología psicosocial que ha generado una imagen del Estado colombiano distorsionada y paradójica, básicamente porque: 
[...] sufre una escisión profunda, similar a la que sufren en su Yo los pacientes de esquizofrenia: se ha construido un "Yo estatal" legal e ideal, emanado del Estado de Derecho, a cuyos postulados y exigencias afirman ajustarse los agentes en sus desempeños, al lado de un "No-yo estatal", constituido por las prácticas perversas y criminales toleradas y asumidas por el Estado en acuerdos clandestinos, pero cuyos agentes son rotundamente negados como apoyados o relacionados de alguna manera con el Estado, a pesar de su real imbricación en su acción omisiva y aquiescente. Se llega así a la paradoja corriente en la cual, mientras un brazo estatal desplaza y masacra, otro brazo estatal denuncia, abre procesos judiciales inútiles y aprueba leyes de asistencia a las víctimas. Los dos brazos no entran en conflicto gracias a la escisión esquizofrénica del Yo estatal (Giraldo, 2015, pp. 453-454).

Así las cosas, cabe la pregunta de cuál es el lugar que ocupa la transición política en medio de una historia caótica de conflicto permanente entre grupos sociales confrontados que, habituados al paroxismo de la violencia política, han minado las posibilidades para que la sociedad se oriente hacia el curso de la paz y la armonía social.

El lenguaje de la transición política en Colombia se sitúa en el marco coyuntural de la firma de la paz ocurrida en La Habana el 23 de septiembre de 2016, donde el presidente de la República Juan Manuel Santos y el comandante del Estado Mayor de las Fuerzas Armadas Revolucionarias de Colombia (FARC), Rodrigo Londoño - "Timoleón Jiménez" o "Timochenko"-, sellan el fin del conflicto con esta guerrilla. Dice Cruz Rodríguez (2016):

El acuerdo sobre justicia transicional, restaurativa y reparadora crea una jurisdicción especial para los crímenes cometidos en el marco del conflicto armado, que cobijaría a todas las partes, los integrantes de la guerrilla y los agentes de la sociedad civil y del Estado, incluyendo los militares. Así mismo, se estableció un plazo de seis meses para la firma del acuerdo final de paz. De esta forma, aunque faltando un trecho importante, el proceso de paz entró en una etapa final a la que nunca se había avanzado y que prácticamente era inimaginable unos años atrás (p.7).

Nuestro propósito en lo que sigue consiste en pensar la transición política en el escenario histórico de la firma del acuerdo de paz en La Habana. Esto se plantea 
al hilo de las contradicciones incubadas en el proceso histórico de la violencia política en Colombia y que aún perviven en nuestro presente. En este orden de ideas, pretendemos situar el horizonte dialógico de la razón comunicativa ${ }^{2}$, de inspiración habermasiana, desde las bases del pensamiento crítico y particularmente de la idea de la posilustración o del movimiento histórico y político de la salida o de la transición de un estado de minoría de edad a otro que en la práctica busca la emancipación humana.

\section{Posilustración y posacuerdo: ¿cómo gobernar en el presente?}

UNA ÉPOCA POSILUSTRADA O POSMODERNA haría las veces de caja de resonancia de las voces filosóficas que aún tienen cosas que decir al presente $(\mathrm{Mu}-$ guerza, 1991, pp. 12-17). Coincidimos completamente con la hermenéutica que propone Michel Foucault del texto en cuestión y que aparece en la publicación El gobierno de síy de los otros, específicamente en la clase del 5 de enero de 1983, donde el francés resalta que la Aufklärung kantiana es una pregunta dirigida en primer lugar al quehacer del pensamiento en el análisis del presente; en segunda medida, al modo como la filosofía se pliega a esta demanda por la actualidad y, en tercera instancia, sobre cómo el filósofo, el sabio o intelectual cumple un

2 Para Habermas la apuesta filosófica del pensamiento ilustrado busca que el uso pragmático de la razón tenga lugar en la deliberación pública bajo el recurso del argumento, la comunicación de los anhelos morales, los juicios de valor y las expresiones artísticas. La vigencia del pensamiento ilustrado se encuentra justamente en su capacidad de leer los problemas sociales (en el caso colombiano sería lo relacionado al problema de la violencia y la idea de la transición política) en un presente que no corresponden específicamente a los asuntos históricos acaecidos en el periodo histórico de la modernidad europea. En este sentido se entiende que el proyecto de la filosofía moderna, en la perspectiva de un pragmatismo de la razón ilustrada (o razón comunicativa según Habermas), se propone iluminar las oscuridades que dominan en el mundo de la vida, usualmente atravesadas por la división de los saberes y la proliferación de los discursos especialistas, las contradicciones sociohistóricas de los pueblos, los escenarios de caos social, un conjunto de variables que se encuentran en el estudio del conflicto y la violencia política en Colombia. Como lo plantea el filósofo alemán: "En la praxis comunicativa cotidiana han de imbricarse interpretaciones cognitivas, expectativas morales, expresiones y valoraciones. Los procesos de comprensión del mundo de la vida precisan de una tradición cultural en toda la amplitud de su horizonte y no solamente en las bendiciones de la ciencia y de la técnica. De este modo, la filosofía podría actualizar su referencia a la totalidad en su cometido de intérprete del mundo de la vida” (Habermas, 2008b, p. 28). 
papel social en este proceso donde la filosofía se atempera a la historia presente, no remitiéndose al antes o al después, sino al ahora (Foucault, 2009 pp. 29-30).

En otras palabras, retomar el proyecto ilustrado implica distinguir el uso pragmático de una razón que, atemperada en los problemas del presente, busca pensar filosóficamente una ética del discurso en aras de considerar la desinstrumentalización del conflicto, que normalmente se alimenta de las maquinaciones estratégicas en pos de la conquista y el mantenimiento del poder político.

En este orden de ideas, los desarrollos adelantados por la teoría de la acción comunicativa se presentan como la actualización sociológica y ética de las cuestiones abordadas por Kant en el siglo XVIII. Al tratarse de un proyecto posilustrado de la filosofía moderna, los ejercicios de justificación de un programa de ética del discurso que emprenden Habermas y Apel son un pretexto ideal para pensar los dilemas ético-morales que atraviesan a una sociedad que pretende encaminarse hacia la transición política.

¿Cuál es el papel de la filosofía en el mundo actual? Es una forma de actualizar la pregunta acerca de qué es la ilustración; un asunto que tiene relación directa con la pregunta de cómo gobernar una sociedad bajo la égida de la ilustración. Tanto la pregunta por el sentido de la ilustración, como la que indaga por la forma de gobierno en una época ilustrada, son cuestiones que coinciden en retomar la pregunta filosófica del quehacer del pensamiento crítico en el análisis y la praxis política del presente. En clave kantiana se argumenta que la actitud de la razón cuyo uso no es doméstico (académico) sino cósmico (universal) pretende resolver los problemas abiertos por la historia de las ideas modernas en contexto. Dicho de otro modo, se trata una filosofía cuya misión y tarea es la de interpretar sus usos teóricos, prácticos y estéticos ${ }^{3}$ en sociedades que se encuentran en un proceso de maduración, es decir, de conducción y de gobierno.

Para Habermas el papel ilustrador de la filosofía se cifra en la distinción entre un quehacer filosófico inscrito en la hermenéutica de la realidad social, que se aleja

3 Como se verá más adelante, la enunciación de los tres ámbitos de la razón trascendental en el ensayo Respuesta a la pregunta... se produce en la caricaturización que plantea Kant de los posibles catalizadores sociales ante un proceso de emancipación: en este sentido se alude al libro, en referencia al ámbito de la razón teórica, al pastor de almas, en dirección a la razón práctica, y a la medicina, en analogía con la crítica del discernimiento. 
del rol de guardiana de la tradición, que ha buscado a toda costa conservar unos saberes heredados, haciendo de las ciencias filosóficas la atalaya a partir de la cual se observa el mundo sin ser ella misma objeto de observación (Habermas, 1990, p. 24). En la perspectiva de Foucault, el problema histórico de la salida de un estado de minoría de edad (que es también un asunto que atañe a la pregunta por la salida al conflicto armado en Colombia) es una analítica que busca describir el modo de proceder de las técnicas de la conducción y del gobierno de los otros.

El dilema de la ilustración tiene que ver con el despotismo de un proceso en el que unos sujetos con privilegios en torno a una episteme, una ética y una medicina se atribuyen el derecho de agenciar procesos de emancipación o de gobierno de los otros. En efecto, el despliegue de la minoría de edad se produce en un proceso de sustitución-dominación en el que el entendimiento y el faro de la razón ilustrada es cambiada por un libro que alecciona pero no transforma, un director de conciencia que retrasa la toma de decisiones autónomas y un médico que receta la dieta y adiestra el cuerpo; en fin, la ilustración tendrá que ver con el modo que tienen los sujetos en la modernidad de gobernarse y ser gobernados (Foucault, 2009, p. 46).

En este orden de ideas, tanto el posconflicto como la posilustración son escenarios históricos en los que el proyecto emancipatorio permanece en la indefinición o, en palabras de Kant, en proceso. En este sentido, el proyecto sociológico de la teoría de la acción comunicativa como programa de fundamentación para una ética del discurso es un modelo de una racionalidad que justifica, interpreta y hace las veces de comodín, ofreciendo escenarios de comprensión para que el científico social pueda trazar una lectura crítica sobre un contexto que carece por completo de alusiones al pasado, de conexiones de sentido y de memoria. La misión filosófica de extender un puente de comprensión en los vacíos y lagunas que dominan por doquier en una situación social plagada de conflictos y tensiones alrededor de las formas de gobierno, explican la vocación hermenéutica de una filosofía inmersa en los asuntos que conciernen a la actualidad:

Los procesos de comprensión del mundo de la vida precisan de una tradición cultural en toda la amplitud de su horizonte y no solo de las bendiciones de la ciencia y la técnica. De este modo, la filosofía podría actualizar su referencia a la totalidad en su cometido de intérprete del mundo de la vida. Cuando menos podría ayudar a poner en movimiento de nuevo la articulación inmóvil 
de lo cognitivo-instrumental con lo práctico-moral y lo estético-expresivo, todo lo cual está paralizado, como una maquinaria que se obstinara en detenerse (Habermas, 2008a, p. 28).

Esta misma actitud crítica frente a una filosofía que no se preocupa por los problemas del presente tiene lugar en la obra Pensamiento postmetafísico, donde Habermas (1990) esgrime que el horizonte de la modernidad se ha alejado de los atributos trascendentales de la razón, tales como la universalidad, la incondicionalidad y la sistematicidad, para poder leer las preguntas clásicas de la filosofía moderna a partir de la inmanencia de las circunstancias: "la conciencia trascendental ha de concretizarse en la práctica del mundo de la vida, ha de cobrar carne y sangre en materializaciones históricas" (p. 17).

Ahora bien, la transición política en Colombia se puede asimilar a lo que el filósofo Estanislao Zuleta denominó la transformación democrática, entendiendo con ello el paso de la guerra generalizada practicada entre las instituciones del Estado y los grupos beligerantes alzados en armas, hacia una instancia de diálogo en donde predomina el camino de la sensatez que, renunciando a la lógica autodestructiva de la guerra y la dictadura militar, procura el restablecimiento de la confianza en la justicia, situación que en la práctica requiere de una esperanza depositada en la capacidad de organización y participación del pueblo (Zuleta, 1990, pp. 131-132). Será el pueblo y su potencia para la organización política (juntas comunales, movimientos sociales, etc.), la fuerza material para que el Estado legisle y administre justicia en función de los intereses de las mayorías en Colombia, generalmente excluidas de los procesos de transformación democrática.

\section{Modernidad suave, ilustración y violencia}

Pensar el posacuerdo y la transición política en Colombia implica reconocer que en el uso público de la razón y en el proceso de ilustración que atraviesa una sociedad (entiéndase este como un proceso educativo que toma como base la argumentación, el diálogo y el procedimiento comunicativo), la violencia debe ser sustituida por recursos diferentes de la eliminación sistemática del oponente (Thiebau, 2003, pp. 447).

Como lo plantea de un modo elocuente el filósofo canadiense Charles Taylor, una de las improntas que caracteriza a una sociedad que ha hecho el tránsito 
de la guerra a la paz - una sociedad secular- tiene que ver con su capacidad de abandonar los impulsos sexuales y tanáticos que promueven la violencia. En otras palabras, es a través de los instrumentos para la autocorrección o automodelación -entre los que cabe mencionar las técnicas para el disciplinamiento moral y las políticas de gobierno encaminadas al adiestramiento y la conducción de los impulsos sexuales, o dominio de la naturaleza- como se alcanzan niveles de civilidad óptimos que contribuyen a un continuo proceso de pacificación social (Taylor, 2014, pp. 185-190).

El conflicto tendría entonces que pasar del agotamiento de los recursos instrumentales ínsitos en las confrontaciones bélicas, para ser trasladado a un escenario atemperado por los procesos comunicativos y la pragmática del lenguaje. En este sentido, el ensayo Respuesta a la pregunta: ¿Qué es la ilustración? se presenta como una caja de herramientas que, suavizada por la teoría de la acción comunicativa habermasiana, ofrece luces para asumir la comprensión filosófica de un conflicto que podría escenificar sus tensiones y representar de un modo argumentado sus pretensiones políticas y morales en el plano de una ética discursiva, a pesar de ser el más largo en el hemisferio occidental.

Sobra decir que la violencia incluye en su accionar el lenguaje y las acciones instrumentales, maquinadas y calculadas en pos de la destrucción del enemigo. En la perspectiva kantiana, la violencia tiene lugar en la naturalización moral de la domesticación ejercida por el poder pastoral, también personificado en los tutores de pensamiento o los amaestradores de masas ${ }^{4}$; en el afianzamiento de la

4 Hoy hablaríamos del papel decisorio que juegan los medios de comunicación en la construcción de un espacio público, o de cómo las élites adineradas e influyentes ejercen poder sobre un electorado moldeable y corruptible. Muestra de ello fue el resultado del plebiscito de octubre de 2016 en Colombia. Se trató de un resultado que estuvo sometido al juego de las posiciones políticas, desde el gobierno y en cabeza del líder negociador en La Habana, se encontraba Humberto de la Calle, quien sostuvo la necesidad de legitimar los acuerdos entre el Estado y las FARC a través del voto popular, con el objeto de blindarlos y darles un curso institucional. Esta apuesta política buscaba una decisión afirmativa de un electorado que de cierto modo tendría un compromiso moral y emotivo frente a una larga historia de guerra y donde el voto por el 'Sí' posiblemente revelaría las intenciones de perdón y reconciliación de los colombianos. De otra parte, las posiciones antagónicas a este proceso jurídico y de política para la paz, particularmente las provenientes de las huestes uribistas, hicieron una campaña consistente en desprestigiar el acuerdo y su legitimación en el plebiscito, recurriendo a opiniones sin fundamento, prejuicios y temores reunidos en el señalamiento de que, de aprobarse el acuerdo firmado en La Habana entre el Estado y la guerrilla 
pereza y la cobardía o moral de la conducción pasiva, cuyo propósito es el adiestramiento; en el despotismo ilustrado y de manera definitoria en el análisis del uso privado de la razón.

La pregunta por la ilustración es entonces una cuestión que indaga por la superación de la razón instrumental, la cual se ramifica en diversas manifestaciones propias de la minoría de edad. En otras palabras, la actualización del proyecto ilustrado, y en concreto del problema de la salida de una condición humana preilustrada, será planteado por Habermas al asumir que la razón pública en el escenario de una ética del discurso es un capítulo de consideración dentro del programa de una filosofía moral en la que Kant dialogaría junto a las propuestas de Kurt Baier, Marcus George Singer, Jhon Rawls, Paul Lorenzen, Ernst Tugendhat y Karl-Otto Apel (Habermas, 2008a, p. 54).

Desde el habla hispana, ha sido la filósofa Adela Cortina una de las continuadoras del proyecto filosófico de la ética discursiva, acentuando el papel pragmático de un enfoque ético que propende por el diálogo concertado, la argumentación y la pragmática comunicativa, escenarios sui generis que van más allá de la racionalidad estratégica, toda vez que presuponen un ejercicio reflexivo cuya consumación es la racionalidad discursiva, principio que estructura a la ética del discurso (Cortina, 2003, p. 538).

Sin embargo, conviene distinguir que la recuperación del proyecto ilustrado no retomará el papel de la fundamentación racional de una modernidad que se busca a sí misma o, como también algunos pensadores latinoamericanos han leído, desde el marco de un proyecto de dominación cultural que extirpó los saberes y los lenguajes locales, para devenir en un programa geopolítico patrocinado por las metrópolis en pos del ordenamiento político, económico y educativo de las colonias de ultramar (Castro-Gómez, 2010).

Hablar de una modernidad suave, atemperar la razón emancipada o descentralizada, como lo plantea Habermas (1990, p. 44), tiene por objeto recuperar

más antigua en Latinoamérica, se avanzaría en la consolidación del castrochavismo en Colombia. A ello sumaron afirmaciones derivadas de esta ficción comunicativa, relacionadas con la desaparición de la propiedad privada o la pérdida de la dignidad de las fuerzas militares. Con estos recursos publicitarios y de comunicación, la campaña por el 'No' salió avante, y los resultados del plebiscito por la paz jamás pudieron pasar bajo la tutela afirmativa de la voz popular. 
y actualizar los insumos teóricos y procedimentales que permiten avanzar en la compresión de una ética que se construye sobre la base de los recursos argumentativos, el mundo de la vida y la pragmática del lenguaje. De ahí que Habermas reconozca que el suelo nutricio de una ética filosófica no se encuentra en la teoría del conocimiento, sino en una teoría especial de la argumentación (Habermas, 2008a, p. 55).

La actualización de la ética ilustrada en el escenario de la ética del discurso parte inicialmente de una moción de orden metodológico cuyo referente más inmediato es el carácter fenomenológico de los sentimientos morales y la genealogía de un juicio moral que nos traslada a un plano que se ubica en el más acá de las condiciones de posibilidad de un razonamiento moral. Es en la contingencia de los afectos -y particularmente en la perspectiva abierta por Strawson al distinguir entre los sentimientos de indignación, resentimiento y vergüenza, una triada cuyo propósito consiste en poner de manifiesto que la insatisfacción moral nace a partir de un conflicto en el que los agravios afectan a los sentimientos morales- que estos mismos se integrarán en el enjuiciamiento de los conflictos éticos y motivarán los procesos pragmáticos de enunciación que integrarán a la comunidad dialogante. Este será pues el tratamiento terapéutico que hará una ética filosófica a una pregunta de talente normativo del tipo “¿qué debo hacer?":

Las preguntas de moral práctica del tipo “¿qué debo hacer?” deben desterrarse de la reflexión racional, al menos en la medida en que no se pueden resolver con los criterios de la racionalidad finalista. Esta patología de la conciencia moral moderna requiere una explicación teórico-social; la ética-filosófica que no pueda dar tal explicación ha de proceder de modo terapéutico [...]. En este sentido, la fenomenología lingüística de la conciencia ética que ha elaborado P. F. Strawson en su célebre trabajo Freedom and Resentment ( $L i-$ bertad y resentimiento) supone una fuerza mayéutica capaz de abrir los ojos del escéptico moral (que se presenta como un empirista) ante las intuiciones morales de su propia vida cotidiana (Habermas, 2008b, p. 55).

El tratamiento terapéutico de una ética filosófica que dé cuenta de la comprensión del conflicto armado en Colombia es un elemento sustantivo en lo que se ha denominado como transición política, o el paso de un estado de guerra 
hacia un estado de paz. Este elemento ha sido considerado por la ciencia social colombiana. Para ello baste evocar el trabajo de Gonzalo Sánchez Gómez, quien en Guerras, memoria e historia (2006), sitúa el foco del análisis del conflicto colombiano en su enfermiza prolongación, que incluso ha ido más allá de la experiencia de las dictaduras militares vividas en Latinoamérica durante la segunda mitad del siglo XX.

Esta situación inquietante plantea el interrogante de cómo superar la lógica insistente y testaruda de una sociedad que ha perpetuado la guerra como principal mecanismo para el control social. Pensar entonces una posible salida al conflicto en la perspectiva de Sánchez Gómez es semejante a la idea de modernidad suave que hemos venido planteando.

Ello es así porque para el investigador del IEPRI, una de las rutas para desandar el camino de las guerras cíclicas en Colombia tiene que ver con la recuperación de la memoria, entendiendo con ello la reivindicación de una suerte de "inteligencia de las víctimas", absolutamente real, contingente y vivencial (Perea, 1990, p. 167), que exterioriza la vulnerabilidad olvidada por el paroxismo de la violencia política.

La memoria es una historia de vida que se funda en la existencia afectiva de las personas involucradas en la dinámica de la guerra (usualmente las víctimas) y se sitúa en la lógica de la reflexividad y la empatía que genera la ilustración de los afectos o, en la formulación de Strawson, en la perspectiva de la teoría de los sentimientos morales. La memoria es el relato de las víctimas que no ha sido reivindicado como mecanismo moral y político en aras de contribuir en la terapéutica ética y de acción comunicativa que requiere el país. Ha sido justamente la insistencia de poner en práctica la lógica de la guerra en Colombia lo que ha impedido una transición política que incluya la historia de las víctimas del conflicto armado.

En clave kantiana y particularmente en referencia al texto del que hacemos mención, se produce la impresión de que los sentimientos son decapitados de raíz justo cuando la razón reclama para sí misma la mayoría de edad: desde la divisa ilustrada, la subjetividad no puede quedar expuesta al abandono de la heteronomía de los afectos.

Mostraremos a continuación cómo se produce esta asunción de la razón como un factor idóneo en la salida del hombre de la condición de menor de 
edad o, como buscamos leerlo en los acápites que vienen, cómo la ilustración es al mismo tiempo una pregunta que indaga por el modo de gobernar a los otros.

Explicitaremos algunas técnicas de gobierno que se desprenden de Respuesta a la pregunta: ¿Qué es la ilustración?, cotejando sus principales tesis con textos críticos posteriores, particularmente al retomar el uso estético de la razón, escenario de la filosofía crítica donde se privilegia un acercamiento hacia la reflexividad y la empatía, potencias que identifican a los humaniora o los conocimientos humanísticos.

5. Primera técnica de gobierno: la ilustración de los afectos

UNA DE LAS PREGUNTAS ÉTICAS Y POLÍTICAS relacionadas con la cuestión de la desinstrumentación del conflicto tiene que ver con la salida de la violencia, es decir, si es posible explorar alternativas que superen un escenario de conflicto minado por la confrontación de lógicas instrumentales que se baten por la conquista y el mantenimiento del poder político. Pretendemos entonces leer el problema de la salida de la violencia en analogía a la salida de una época dominada por la minoría de edad.

En el breve opúsculo Respuesta a la pregunta..., el filósofo alemán declara que la ilustración es la salida del individuo de su autoculpable minoría de edad. La ilustración es entonces la salida de un estado de barbarie e incivilidad hacia uno donde predomina el buen sentido y la reflexividad. Un siglo más tarde el filósofo Edmund Husserl interpretará esta divisa como la posibilidad que se presenta a la humanidad para ingresar al reino de la actitud filosófica, un asunto que implica la renuncia a la condición de siervo de la materia y la cotidianidad (actitud natural).

En la perspectiva fenomenológica, el paso de la actitud natural a la actitud filosófica, si bien constriñe a la subjetividad a abandonar la acritud y la ausencia de cuestionamiento, no pierde de vista que son la corporeidad y una razón encarnada en el mundo de la vida los registros filosóficos que familiarizan el mundo abstracto de las ideas con el de las cosas mundanas.

En clave kantiana, la salida tendría que extirpar la cercanía con los afectos, para levantar la voluntad hacia una suerte de autarquía de la razón, pero sin perder de vista su vinculación con el mundo de la vida, es decir, con los compromisos éticos y políticos que se presentan en una realidad social en proceso de ilustración. 
En este sentido, cabe la pregunta de cómo Kant entiende la minoría de edad. Para el filósofo se trata de una incapacidad que habita en el sujeto, originada por la falta de valor y de decisión, virtudes que, puestas en práctica, supondrían la liberación ante la conducción que pudiera ejercer un guía espiritual o un pastor de almas. En este sentido la mayoría de edad es la divisa de la ilustración (sapere aude), es decir, el valor radical de la autonomía en la persona o el hecho de que bajo el uso del entendimiento se libere de las cadenas que lo atan al mundo de la superstición, la autoridad o la falsa creencia. Esta idea se condensa en una categoría decisiva para el filósofo de Königsberg: emancipación.

Ahora bien, en la perspectiva amplia de la filosofía crítica, la emancipación no solamente se pone de presente en la reivindicación de la autonomía moral frente a un estado de docilidad acrítica, sino que también la ilustración implica el conocimiento de los afectos del otro, a lo que Kant se refiere como a un universal sentimiento de empatía.

Emancipación como salida de la minoría de edad e ingreso al reino de la adultez moral implica reconocer que el agravio vivido por otro genera sentimientos de humanidad, es decir, que la empatía y la reflexividad aligeran el ímpetu de la autonomía en su voluntad autárquica de liberación de los afectos, para situarse en la mundanidad de lo sociable que Strawson identificará en el ámbito del conflicto moral, y donde se activará la indignación, el resentimiento y la vergüenza.

Estos sentimientos conflictivos son insumos motivacionales de los juicios morales que harán parte del ejercicio comunicativo de las comunidades dialogantes, tal y como lo propone Habermas en la propuesta de una teoría de la acción comunicativa.

El universal sentimiento de empatía, categoría usada por Kant en el ámbito de la Crítica del juicio, es una experiencia humana comprensible en la vivencia de la comunicación. La analogía o el "como si" simbólico que enlaza al bien moral con el juicio de lo bello, se manifiesta en el sentimiento de empatía, expresión comunicativa que propicia la sociabilidad y es condición de posibilidad para la creación de las artes y de la cultura. El sentimiento universal de empatía es una propiedad específica de la sociabilidad, que se consolida a través de la relación del juicio de lo bello con lo que ha denominado Kant la cultura de las facultades del espíritu. La relación que se propone entre el juicio de lo bello y la cultura es el atributo estético que define el mundo humano: 
La propedéutica a todo arte bello, en la medida en que está dirigida hacia el más alto grado de su perfección, no parece residir en preceptos, sino en la cultura de las fuerzas del ánimo a través de aquellos conocimientos previos a los que se denomina humaniora; presumiblemente porque humanidad designa por una parte el universal sentimiento de simpatía, y por otra la facultad de poder comunicarse íntima y universalmente; propiedades que, enlazadas, constituyen la sociabilidad apropiada a la humanidad, por lo cual ella se distingue de la estrechez animal (Kant, $K U, \$ 60,259$, p. 307).

Si bien la emancipación implica una experiencia del tránsito en donde se pretende superar la inmanencia de los afectos o la subordinación placentera de los sentidos, que se obnubilan ante el poder seductor de la técnica de gobierno del tutor del pensamiento, hacia una trascendencia buscada, a saber, la autonomía y la liberación, esta misma reconocerá en un auditorio general o de razón pública la comunicación del sentimiento de empatía.

Los conocimientos humanísticos aportan en la suavización de la razón ilustrada y son puente para dimensionar el talante afectivo e inmanente de los sentimientos y que Strawson identificará dentro de un proceso de elaboración del juicio moral. Habermas acoge la teoría de los sentimientos morales, dado que modifica de un modo sustancial el enjuiciamiento ético; su naturaleza no les permite erigirse sobre la base de una racionalidad autosuficiente y normativa. En este sentido, la teoría de la acción comunicativa, al tener como escenario la ética del discurso, parte originariamente de un presupuesto fenomenológico que se manifiesta en la capacidad vinculante que tienen los sujetos de consentir y disentir con sus sentimientos morales frente a las repercusiones de un hecho en conflicto, y así transgrede las nociones convencionales o socialmente aceptadas de bondad y bienestar social.

Con ello se aclara que el enjuiciamiento moral no implica el disciplinamiento racional de los sentidos y los afectos, sino al contrario, su promoción en procesos intersubjetivos de conocimiento que se tornan en la práctica indispensables para identificar y dar trámite a los agravios morales desatados en un conflicto social. En el acompañamiento de los sentimientos morales, esto es, de los insumos éticos de carácter fenomenológico, se fortalece el tejido social.

Así las cosas, tres tesis se desprenden del proceso de salida de la violencia desde una perspectiva abierta, plural y "suave" del proyecto de la ilustración y su 
efecto en una teoría ética del discurso, es decir, en una propuesta ética que desde la filosofía contemporánea ofrezca horizontes de sentido para proyectar una sociedad en paz en un escenario de transición política en Colombia:

1. Localizar la pregunta kantiana acerca de qué debo hacer y qué debemos hacer en los tiempos de la posilustración se resuelve recíprocamente en un movimiento de salida, que va de la minoría de edad a la mayoría de edad en un ámbito que compete a la voluntad del individuo -autonomía en un sentido trascendental o competencia argumentativa en un sentido pragmático-. Lo anterior se logra una vez se reconoce el paso de la indiferencia y la frialdad frente al sentimiento humanitario de empatía o sociabilidad, que involucra el apalabramiento del mundo moral que ha sido lesionado a través del juicio de reflexión, una cuestión que ya no depende de una perspectiva individual -autarquía moral de los deseos de emancipación- sino de un compromiso declarado ante un colectivo -la empatía comunicacional, reflexiva y los sentimientos morales integrarían lo que hemos denominado como la emancipación de los afectos-.

No hay salida de la violencia si la razón emancipada extirpa de raíz sus vínculos morales y estéticos con los sentimientos humanitarios de la empatía y la posibilidad que tienen estos mismos de ser manifestados o comunicados en el ámbito de lo público. Al definirse la emancipación como un proceso de socialización de los sentimientos de empatía y bajo la égida del juicio de reflexión, la desinstrumentalización del conflicto implicará la salida de la violencia en la perspectiva de los humaniora, o los conocimientos humanísticos, saberes necesarios en la consolidación de un proceso de alfabetización cultural de una sociedad, que tendrá como faros orientadores el arte y los conocimientos estéticos.

2. La razón por la cual el juicio de reflexión es el encargado de hacer el tránsito de lo individual a lo comunitario se descubre en la pretensión kantiana de resolver el problema metafísico de la filosofía crítica, a saber, ¿̇ómo extender un enlace o puente que comunique los usos práctico y teórico de la razón? En una publicación del profesor Hoyos titulada Los intereses de la vida cotidiana y las ciencias (1986) se plantea que en la teoría estética kantiana, además de resolverse la dialéctica entre 
teoría y praxis, fenómeno y noúmeno, libertad y naturaleza, se apunta a un reordenamiento del saber científico técnico a partir del principio de causalidad teleológico, el cual abandonaría el primado de la explicación de los fenómenos según el paradigma mecanicista de la física newtoniana, para acoger las comprensiones éticas en orden a una finalidad orgánica con efectos en la cohesión social. Ni el saber científico ni el técnico, como tampoco el normativo, estarían fuera de esta exigencia de una teleología reflexiva con pretensiones de reinventar las relaciones entre el individuo y el todo. La propuesta habermasiana de otorgar una finalidad que va más allá de la relación causa-efecto y que por costumbre ha explicado el mecanismo del razonamiento instrumental (basta mencionar las lógicas de la guerra que se han usado como insumos teóricos para entender el despliegue social y político del conflicto armado en Colombia) tiene antecedentes en la teleología que otorga Kant al juicio de reflexión. De esta manera lo plantea el profesor Hoyos (1986):

Por tanto, la facultad reflexionante de juzgar, como posibilidad de pensar lo general a partir de lo particular, ofrece a la razón una idea global de la naturaleza como conjunto de leyes empíricas causales, susceptibles en su conjunto de ser atravesadas por una nueva determinación de otra especie, que les confiera un nuevo sentido, que pueda dar la idea de fin a un conjunto de leyes empíricas, organizándolas como medios posibles.

En esta concepción de Kant sobre la facultad reflexionante de juzgar como mediadora entre la teoría y la praxis, se puede apoyar la propuesta de pensar la ciencia y la técnica en su conjunto como un saber instrumental por finalidad. En realidad el sentido de la acción instrumental responde adecuadamente al sentido del principio de causalidad natural, que deja abierta la posibilidad de pensar la naturaleza en términos de determinismo absoluto o de disponibilidad. Pero si se tematiza la finalidad como posibilidad de disponer y orientar este conjunto de conocimientos con base en principios de la razón práctica, se supera el determinismo y se da a la disponibilidad de su auténtico sentido. 
La propuesta de entender la ciencia y la técnica como acción instrumental por finalidad, dejando la determinación de los fines en el ámbito de la acción por la comunicación, como parece sugerirlo Habermas, tiene por tanto sus raíces en la filosofía crítica de Kant (p. 17).

3. Strawson ampliará el ámbito de los sentimientos morales en una red de relaciones en donde confluirán la indignación, el resentimiento y la vergüenza. Habermas verá en este tinglado motivacional los insumos fenomenológicos para las justificaciones práctico-morales que se producen en la praxis comunicativa cotidiana (Habermas, 2008, pp. 57-60). También en ellos la desinstrumentalización da lugar a que los juicios práctico-morales graviten alrededor de un lugar distinto al del bienestar social, a la relación entre medios y fines, para ser usados en un escenario de racionalidad que no desactiva la intensidad teórica de la justificación moral, sino que al contrario relativiza el juicio moral por sus implicaciones sociales según la confluencia de los afectos en un proceso comunicacional abierto y plural:

La fenomenología de la moral de Strawson, por lo tanto, llega a la conclusión de que el mundo de las manifestaciones morales únicamente se deriva de la actitud realizadora de los partícipes de la interacción, que los sentimientos y las reacciones afectivas personales en general remiten a pautas suprapersonales del enjuiciamiento de normas y mandatos; y que la justificación práctico moral de una forma de acción se orienta hacia otro aspecto distinto del enjuiciamiento afectivamente neutro de las relaciones entre los medios y los fines, incluso aunque esta se deduzca de los puntos de vista del bienestar social [...]. Está claro que los sentimientos tienen la misma importancia para la justificación moral de las formas de actuación que la percepción para la explicación teórica de los hechos (Habermas, 2008b, pp. 60-61).

\section{Segunda técnica de gobierno: la trascendencia comunicativa}

LA FENOMENOLOGía de LOS SENTIMIENTOS MORALES permite afirmar que la corrección normativa de los enunciados que se enmarcan en la pregunta ética 
de qué debo hacer parte originariamente de una serie de conflictos y disonancias que se desatan en la cotidianidad o mundo de la vida. Ahora bien, Habermas explora desde esta base inmanente de las afecciones morales y desde el plano de las declaraciones emotivas, las pretensiones de universalidad en orden a una teoría de la acción comunicativa (Habermas, 2008 pp. 68-69). Es decir, que una valoración filosófica de los sentimientos morales y su conexión con el lenguaje será examinada a partir de una teoría de la verdad que, lejos de cuestionar su carencia de fundamentación (un asunto que de suyo ni le compete por la naturaleza misma del agravio moral y de su juicio), será pensada en orden a una concepción ética de la corrección normativa y de manera directa con una cierta teoría de la argumentación.

Traduciendo esta misma exigencia de justificación racional, podríamos esgrimir que en el ensayo sobre la pregunta por la ilustración, Kant ve en la pereza y la cobardía los grilletes morales que impiden el ingreso del sujeto a un mundo ilustrado, pues se presentan como los insumos motivacionales que se pliegan a una moral de la conducción y la domesticación, alejando al sujeto tanto del idealismo normativo del sapere aude como de la reflexividad y la empatía comunicativa que caracteriza a la ilustración de los afectos. Veamos cómo Kant profundiza en esta analítica de los afectos que impiden el proyecto ilustrado para luego explorar la asunción normativa en el plano de la razón pública, un asunto de interés para el modelo argumentativo explorado por Habermas e incluso por el mismo Apel.

Pereza y cobardía son los obstáculos que niegan de plano la mayoría de edad. Pero la comodidad se presenta muchas veces como una cadena más pesada. Pues en la cotidianidad resulta más fácil legarle a un tutor del pensamiento la tarea de pensar. La comodidad reproduce de manera silenciosa la sumisión y la obediencia y regresa al ser humano a su estado de menor de edad. Es muy sencillo gobernar a un pueblo que le ha dejado a sus guías espirituales los destinos en materia de ciencia y educación.

Otro de los escenarios planteados en el ensayo de Kant tiene que ver con los tutores o los pastores espirituales. Quienes renuncian a la salida que ofrece el sapere aude terminan por dejarle la laboriosa tarea a ciertas personalidades que asumen con gusto el control de las mentes de los sumisos. Por doquier vemos en nuestra sociedad tutores del pensamiento que propenden por una falsa ilustración, en el sentido de que sin apelar a la razón de sus interlocutores, inducen estados de ánimo, mueven los afectos, recrean mundos imaginarios, refuerzan una 
falsa actitud positiva. En otras palabras, Kant denuncia en su ensayo la falsa apariencia que adquieren ciertos hombres ilustrados -hoy diríamos ciertos dispositivos para el control mediático de las masas-, al pretender asumir la mayoría de edad como una técnica para la domesticación. El peligro de esta falsa ilustración consiste en que a los gobernados por estas estrategias de conducción les cuesta liberarse, pues el pastor de almas o el confesor de los afectos plantea en su técnica de domesticación amenazas y castigos, reprimendas morales que evitan que los menores de edad puedan ingresar a un estado ilustrado, es decir, que puedan ir más allá del círculo de la dominación.

La crianza y el poder domesticador que caracteriza a la minoría de edad se define en función de un proceso educativo en donde las amenazas, los chantajes, los premios y los castigos tienen por propósito el gobierno de los otros. Cuando la ilustración se convierte en un proceso de domesticación se descubre que la auténtica naturaleza que gobierna a los individuos es la de la infancia y el tutelaje. Las técnicas para el amansamiento son un conjunto de manuales de reglamentación que actúan en detrimento de la emancipación y la conquista de la mayoría de edad. De ahí que el filósofo de Prusia destaque con resignación que son pocos quienes logran con el "esfuerzo del espíritu" salir de la minoría de edad y, así, andar con paso seguro por los senderos la vida.

En este sentido, si los afectos son manipulables por un instructor de almas, ¿cómo explorar la trascendencia normativa? En un sentido kantiano, ¿hasta qué punto el gran público o la realidad pública -o la república- accede a un estado de ilustración?

Solo es posible pensar la ilustración en la perspectiva de lo público, es decir, siempre y cuando sea la libertad el principio moral que despierta la autodeterminación del sujeto para alcanzar la ilustración. Sin embargo, la ilustración no se produce con la declaración del tutor emancipado, quien liberándose a sí mismo de la condición de menor de edad, propone una sublevación del modelo de la domesticación y la crianza de las almas a sus gobernados. No actúa como ilustrado quien declara ante el público que se ha liberado y por este motivo se propone emancipar a los demás. Este fenómeno se conoce como el despotismo ilustrado y no contribuye en el proceso histórico de la emancipación. Al contrario, refuerza la dominación del pueblo sobre la base de las salidas ejemplares de sus dominadores, un asunto que multiplica los prejuicios, las muletillas del pensamiento y las prótesis de ideas. 
Ahora bien, si el uso público de la razón es la salida que tiene el proyecto de la emancipación -promover un proceso social de liberación en la búsqueda de alternativas razonadas por parte de una comunidad de lectores críticos y con potencial argumentativo para poner en cuestión la opresión que caracteriza a las formas de dominación ínsitas en el despotismo ilustrado-, en la perspectiva habermasiana se entenderá que esta vocación normativa del lenguaje moral, si bien busca la corrección a partir del refinamiento de los argumentos, amplía el proceso de la razón pública a partir del paradigma de la razón comunicativa. $\mathrm{Ha}$ bermas define este proyecto como un ejercicio mediado por los actos de habla, en donde se compromete la palabra en los ámbitos de la verdad (el conocimiento científico), la rectitud (el razonamiento práctico, la conciencia moral y la ética normativa) y la veracidad (la experiencias de cultura, las creencias religiosas, los sentimientos y los juicios de gusto).

Estos son escenarios filosóficos que colindan con los ejercicios kantianos de los tres mundos abordados por la razón crítica y que hacen parte de la analítica racional de la filosofía crítica en los caminos teórico, práctico moral y teleológico. En clave habermasiana este tríptico problemático de la filosofía crítica tiene lugar en la pragmática lingüística de la comunicación, al situar en el escenario de los acuerdos y disensos el desvelamiento de lo que acontece en el mundo de lo real, de las relaciones interpersonales y de las vivencias axiales de la subjetividad:

Llamo comunicativas a las interacciones en las cuales los participantes coordinan en común acuerdos a sus planes de acción; el consenso que se consigue en cada uno se mide por el reconocimiento intersubjetivo de las pretensiones de validez. En el campo de los procesos de entendimiento lingüísticamente explícitos, los actores plantean pretensiones de validez con sus acciones de habla, en la medida en que se ponen recíprocamente de acuerdo y se trata, además, de pretensiones de verdad, de rectitud, de veracidad, según se refiera en cada caso a algo en el mundo objetivo (como la totalidad de las realidades existentes), a algo en el mundo social conjunto (como la totalidad de las relaciones interpersonales legítimamente reguladas) o a algo en el propio mundo subjetivo (como la totalidad de las vivencias a las cuales tiene acceso privilegiado) (Habermas, 2008, p. 69).

Para resumir, el paradigma liberal-republicano es el escenario ético político en el que coinciden las propuestas de Kant y de Habermas. Efectivamente, según 
este modelo de gobierno los ciudadanos que integran a una comunidad políticamente activa se construyen sobre la base de la interacción comunicativa, modo de proceder de la razón en el que, desde una perspectiva pragmática y lingüística, se privilegian las relaciones interpersonales erigidas en la instancia comunicativa y reflexiva que involucran los afectos, la empatía y los sentimientos morales.

Los sentimientos morales son elementos nucleares para agenciar cambios dentro de un proceso de educabilidad o de ilustración para la paz. Y lo anterior parte del contexto que se desprende de un proyecto de transición política que reconozca la particularidad de la inteligencia de las víctimas del conflicto armado en Colombia. Una inteligencia atravesada por memorias y relatos que configuran la relación empática y emotiva que caracteriza a las vinculaciones interpersonales de las víctimas de la violencia, justo cuando han experimentado traumas y dolores causados por la guerra y donde los afectos han permanecido bajo la dominación autoritaria y estratégica de la razón instrumental.

Los escenarios comunicativos de la reflexión empática y la emotividad que caracteriza al sentimiento moral hacen parte de la lógica argumentativa y narrativa para una ética del discurso. La validez jurídica y política de esta pluralidad discursiva es celebrada bajo la existencia de un 'consenso constitucional', que se relaciona con el modus vivendi dentro de un proyecto de Estado democrático socialy de derecho.

Los ciudadanos que integran este modelo de gobierno han ingresado a través de los procedimientos comunicativos a un escenario de justificación racional que ha superado los intereses por conveniencia. El sistema de intereses materiales y particulares que gobierna a los ciudadanos en el mundo de la vida acoge reflexivamente un escenario de universalidad democrática por cuenta de un consenso moral en donde los argumentos se han refinado fruto del uso público de la razón (Muguerza, 2000, p. 21).

\section{A manera de conclusión: ¿̨puede un pueblo domesticado experimentar las mieles de la libertad?}

LA LIBERTAD TENDRÍA QUE SOBREPONERSE ante el despotismo ilustrado. Y Kant define la libertad como aquella capacidad de hacer uso público de la razón. Se hace uso público cuando el intérprete de lo que acontece en la palestra de lo 
público apela a la comunidad de los lectores. En otras palabras, la emancipación tiene cabida en una sociedad alfabetizada, es decir, que vive interpelada por una comunidad de pensadores (o libre-escritores) que, bajo la bandera de la libertad, problematizan la realidad, proponen criterios de análisis para leer el escenario político, generan pensamiento nuevo, es decir, hacen ciencia en función de los intereses sociales.

Sin embargo, Kant descubre que esta idea de la libertad oscila entre un uso privado y público de la razón. El uso privado la razón se encuentra restringido a una comunidad particular de hablantes de un lenguaje común, donde se ponen en práctica códigos de conducta y protocolos de comportamiento muy definidos. En cambio, el uso público a través de la escritura y la lectura se propone apelar al juicio de los lectores. Ahora bien, ¿ por qué apelar a la comunidad de los lectores? Justamente porque en el uso público la razón se vale de argumentos y de la interpelación razonada. La legitimidad filosófica de lo público se produce en el escenario de la disputa del pensamiento que propende por la problematización del mundo abierto de la pluralidad, bajo los instrumentos de la argumentación razonada y la ponderación de los juicios. No hay ilustración si no se parte de la idea de que el pensamiento se materializa en argumentos y estos a su vez buscan crear un auditorio que apela a lo razonable (comunidad dialogante).

Otra cuestión que surge del deslinde de los usos privado y público de la razón tiene que ver con el lugar que ocuparía la ciudadanía. Efectivamente, si el propósito del uso público de la razón consiste en la creación de un auditorio interpelado que pueda someter a juicio el comportamiento adiestrador e inhumano de sus gobernantes, entonces la construcción de pensamiento crítico, esto es, de filosofía emancipatoria, tendría lugar no en el dogma que se reproduce en una comunidad de sujetos, sino en la resonancia de las palabras en el mundo de lo abierto y lo plural.

Ello es así si se parte de la premisa de que la construcción de pensamiento crítico no puede suscribir las verdades de un dogma dentro de un reducto minoritario de individuos que hablan una misma lengua. No resulta conveniente que las personas que se dedican al cuidado de las almas sean al mismo tiempo los sabios que velan por el fomento de la libertad de pensamiento en una perspectiva de lo público.

Este elemento destaca una de las características del pensamiento ilustrado en cuanto a la separación del poder político y de la razón en su uso público, frente 
al uso doméstico y privado que caracterizó al poder religioso. Estas ideas sugieren nuevos cuestionamientos, sobre todo para pensar la relación entre filosofía moderna y educación, por ejemplo bajo las siguientes problemáticas: ¿cómo entender el papel emancipatorio de las comunidades científicas en la perspectiva de lo público? ¿Es la educación el espacio para que el uso público de la razón se ponga en práctica a través de ejercicios abiertos que propicien la interpelación, la argumentación razonada y el estudio ponderado del presente político que nos domina?

En este orden de ideas, cabe preguntar: ¿puede una comunidad apelar al credo particular de su logia para imponer estos mismos valores a la ciudadanía? Esta no es solamente una práctica posible, sino una realidad. El problema de hacer del uso privado de la razón el modelo a seguir para el control social es que retardaría la emancipación del pueblo y haría imposible el cambio generacional a niveles superiores de desarrollo y educabilidad; sería tanto como pisotear los criterios sagrados de los derechos de la humanidad.

Ante la pregunta de si vivimos en una época de la ilustración, Kant responde de forma negativa: lo único cierto es que se encuentra en un proceso. No hay emancipación plena porque la cotidianidad está dominada por los tutores de la domesticación, la minoría de edad y en general por el gobierno de la razón privada.

Pero a diferencia de los tiempos antiguos, la época de la ilustración ha progresado en una mayor conciencia sobre la importancia del ejercicio de la libertad y la construcción del auditorio de los lectores, es decir, de la asunción de la razón pública, conciencia de la mayoría de edad. Como se aprecia, para Kant hay un cierto optimismo sobre una transformación de la sociedad bajo los ideales de la emancipación.

Así las cosas, repensar el papel de la política de la transición, en tiempos donde no es posible hacer el salto definitivo hacia la mayoría de edad, supone asumir una serie de recomendaciones para Colombia en un escenario posible de maduración social y de paz que, en la perspectiva del Padre Giraldo (2015), podríamos resumir en tres variables:

1. La "transformación democrática" en Colombia o el camino hacia la transición política pasa por una apertura hacia la pluralidad comunicativa, proposición filosófica que supone abandonar el monopolio informativo de los canales de comunicación oficiales en Colombia, usualmente 
los encargados de la trasmisión de las mentiras y los ocultamientos de la verdad. En clave kantiana, diremos entonces que la razón pública debe ser respetada como un espacio para la formación política y el disenso argumentado, toda vez que el proyecto de la ilustración reclama de un pueblo en proceso de emancipación la libertad y la razón comunicativa. El pueblo no hará por sí mismo las reformas sustantivas en sus maneras de conducción y de gobierno mientras sea un denominador común el imperio del adiestramiento y la manipulación de la verdad por cuenta de la razón privada que subyace como sustrato de poder en los medios de comunicación masiva en Colombia, coartando las posibilidades del pensamiento crítico y de apertura al disenso (Giraldo, 2015, p. 464).

2. La paz no es simplemente un mecanismo contractual que sellan mediante una firma un conjunto complejo de actores sociales habituados a la lógica de la guerra. Se trata sobre todo de un valor ético, que colinda con los universos humanos de lo espiritual, lo político y lo social. La paz en este sentido es ante todo un proceso de ilustración que no tiene fin, sino que permanece en un prolongado estado de formación. La reivindicación de la memoria de las víctimas, de su inteligencia emocional y del tinglado afectivo que configura su moralidad (resentimiento, indignación y vergüenza), hace parte de un proyecto atemperado de la emancipación política en Colombia, que actúa a contrapelo del terror y la violencia que siembra el carácter siniestro y esquizofrénico de la violencia política que ha marcado la historia social de un conflicto en nuestro país. Mientras la paz no sea un valor político y moral que persiga una sociedad incansablemente, dominará un ambiente marcado por el lenguaje beligerante, la pugnacidad del ataque militar y el exterminio del adversario, y el sentimiento triunfalista de una dirigencia política que cuenta con alegría el número de bajas propinadas en contra del bando enemigo (Giraldo, 2015, p. 464)

3. Una de las mayores muestras de desinstrumentalización del conflicto armado en Colombia tuvo lugar en la exigencia de la dejación de las armas que hizo el Estado colombiano a las FARC como condición fundamental para que este movimiento guerrillero hiciera parte de un proyecto político. El problema de este acto de paz ha consistido en que 
el Estado difícilmente reconoce el uso que ha hecho de la violencia “[...] para perpetrar genocidios de movimientos políticos y sociales, para imponer a sangre y fuego leyes, estrategias y políticas excluyentes, discriminatorias y perversas, las que confunden con la soberanía nacional y el orden constitucional" (Giraldo, 2015, p. 465). El enigma de la democracia en Colombia como el cierre del universo político o la esquizofrenia de Estado, consiste justamente en la ausencia de reconocimiento de las faltas y los excesos que han caracterizado a la violencia política y social en Colombia. La raíz de este desconocimiento tiene que ver con una doctrina de la guerra en la que se ha formado la alta oficialidad militar en Colombia y que, viniendo de las escuelas militaristas de Norteamérica, ha fomentado una ideología anticomunista, antisocialista, antizquierdista (Giraldo, 2015, p. 466). Esta situación requiere de un proceso suave de emancipación al interior mismo de las instituciones del Estado que velan por el uso racional de la violencia y la represión, puesto que:

es imposible construir paz con un ejército adoctrinado para la guerra, y para la guerra cruel, antidemocrática y que ha tenido por objetivo militar amplias franjas de la población civil que se identifican con maneras de pensar que no son las de la élite gobernante y/o de las potencias imperiales (Giraldo, 2015, p. 466)

\section{Referencias}

Castro-Gómez, S. (2010). La hybris del punto cero. Ciencia, raza e ilustración en la Nueva Granada (1750-1816). Bogotá: Editorial Pontificia Universidad Javeriana.

Cortina, A. (2003). La ética discursiva. En: Historia de la ética (Vol. 3). La ética contemporánea (pp. 533-579). Barcelona: Crítica.

Cruz Rodríguez, E. (2016). Fuerza pública, negociaciones de paz y posacuerdo en Colombia. Bogotá: Ediciones Desde abajo.

De Zubiría, S. (2015). Dimensiones políticas y culturales en el conflicto colombiano. En: Contribución al entendimiento del conflicto armado en Colombia 
(pp. 197-246) [Informe de la Comisión Histórica del Conflicto y sus Víctimas]. Bogotá: Ediciones Desde Abajo.

Foucault, M. (2009). El gobierno de sí y de los otros. México: Fondo de Cultura Económica.

Giraldo Moreno, J. (S.J). (2015). Aportes sobre el origen del conflicto armado en Colombia, su persistencia y sus impactos. En: Contribución al entendimiento del conflicto armado en Colombia (pp. 423-467) [Informe de la Comisión Histórica del Conflicto y sus Víctimas]. Bogotá: Ediciones Desde abajo.

Guzmán, Campos, Germán; Fals, Borda, Orlando y Umaña Luna Eduardo (2014). La violencia en Colombia. II Volúmenes. Colombia: Prisa ediciones. Habermas, J. (1990). Pensamiento postmetafisico. México: Taurus.

Habermas, J. (2008a). Ética del discurso. Notas para un programa sobre su fundamentación. En: Conciencia moral y acción comunicativa (pp.53-119). Madrid: Trotta.

Habermas, J. (2008b). La filosofía como comodín e intérprete. En: Conciencia moral y acción comunicativa (pp. 13-29). Madrid: Trotta.

Hoyos Vásquez, G. (1986). Los intereses de la vida cotidiana y las ciencias (Kant, Husserl, Habermas). Bogotá: Universidad Nacional de Colombia.

Kant, I. (1999). Respuesta a la pregunta: ¿Qué es la ilustración? Barcelona: Tecnos.

Muguerza, J. (1991). ¿Una nueva aventura del barón de Münchhausen? (Visita a la comunidad de comunicación de Karl-Otto Apel). En: K. O. Apel, A. Cortina, J. de Zan, \& D. Michelini. (Eds.). Ética comunicativa y democracia (pp. 132-163). Barcelona: Crítica.

Muguerza, J. (2000). Ciudadanía: individuo y comunidad (una aproximación desde la ética pública) [Suplemento 5. Retos pendientes en ética y política]. Contrastes: Revista Interdisciplinar de Filosofia, 5, 17-26.

Palacios, Marco. (1995). Entre la legitimidad y la violencia. Colombia 18751994. Colombia: Grupo Editorial Norma.

Perea Restrepo, C. M. (2006, septiembre $\left.1^{\circ}\right)$. Guerras, memoria e historia. [Reseña del libro Guerras, memoria e historia, de Gonzalo Sánchez]. Análisis Politico, 19(58), 166-173. 
Sánchez, G. (2006). Guerras, memoria e historia. Bogotá: Instituto de Estudios Políticos y Relaciones Internacionales (IEPRI), Universidad Nacional de Colombia-La Carreta Editores.

Taylor, C. (2014). La era secular (Tomo I). Barcelona: Gedisa.

Thiebaut, C. (2003). La escuela de Frankfurt. En: Historia de la ética (Vol. 3). La ética contemporánea (pp. 441-480). Barcelona: Crítica.

Zuleta. E. (2003). La violencia política en Colombia. En: Colombia: violencia, democracia y derechos humanos (pp. 119-133). Medellín: Hombre Nuevo Editores - Fundación Estanislao Zuleta. 